\title{
O ENSINO DE FILOSOFIA E O DESENVOLVIMENTO DA AUTONOMIA
}

Uma proposta de prática pedagógica para o Ensino Médio

\section{TEACHING OF PHILOSOPHY AND THE DEVELOPMENT OF THE AUTONOMY}

A proposal of a pedagogic practice for High School

Rafael Batista

(rafaelbatistafilosofia@gmail.com)

\section{RESUMO}

Este trabalho pretende pensar o ensino de filosofia no ensino médio associado ao desenvolvimento da autonomia em termos kantianos. A partir disso, tem por objetivo propor uma prática pedagógica sobre filosofia política que esteja alinhada à fundamentação teórica.

Palavras-chave: ensino de filosofia política; autonomia; filosofia no ensino médio.

\section{ABSTRACT}

This work intends to think the teaching of philosophy, in High School, associated with the development of autonomy in Kantian terms. From this, the objective is to propose a pedagogic practice on Political Philosophy, which is aligned to the theoretical grounding.

Key words: teaching of political philosophy; autonomy; philosophy in high school.

\section{A filosofia no ensino médio e suas possibilidades}

A filosofia como componente curricular da educação básica sempre viveu uma situação desafiadora em nosso país. Entre idas e vindas no currículo oficial da educação básica, destacase sua eliminação no período pós-1964, em virtude de sua natureza crítica, sendo retirada pela reforma empreendida pela Lei no 5.692/71. Em julho de 2006, a Câmara de Educação Básica do Conselho Nacional de Educação aprovou o Parecer CNE/CEB no 38/2006,

\footnotetext{
${ }^{1}$ Mestrando em Filosofia pela Universidade Federal do Paraná (UFPR).

CV Lattes: http://lattes.cnpq.br/0862929689910078.
} 
propondo a inclusão das disciplinas de Filosofia e Sociologia. Efetivamente, seu retorno é marcado pela promulgação da Lei Federal $\mathrm{n}^{\circ}$ 11.684, de 2 de junho de 2008, acrescentando o Inciso V ao Artigo 36 da Lei de Diretrizes e Bases (LDB): "serão incluídas a Filosofia e a Sociologia como disciplinas obrigatórias em todas as séries do ensino médio". Passados alguns anos, um novo cenário de instabilidade paira sobre a presença da disciplina de Filosofia na educação básica, agora instituída por meio da obrigatoriedade de "estudos e práticas" no Ensino Médio, perdendo a caracterização de componente curricular obrigatório - mudança instituída pela Medida Provisória MPV nº 746/2016. O cenário é incerto, pois a presença e os rumos do trabalho com filosofia no ensino médio ainda serão definidos, após a homologação da Base Nacional Comum Curricular (BNCC), pelas redes de ensino.

É valido observar que essa crise instaurada no ensino de filosofia no Brasil é efeito de uma crise mundial que se materializa em um projeto restritivo para a área das humanidades.

Tanto no ensino fundamental e médio como no ensino superior, as humanidades e as artes estão sendo eliminadas em quase todos os países do mundo. Consideradas pelos administradores públicos como enfeites inúteis, num momento em que as nações precisam eliminar todos os elementos inúteis para se manterem competitivas no mercado global, elas estão perdendo rapidamente seu lugar nos currículos e, além disso, nas mentes e nos corações dos pais e filhos. (NUSSBAUM, 2015, p. 4)

Diante desse cenário, intensifica-se a necessidade de compreender o papel da filosofia na educação básica e sua contribuição para a formação de jovens e adolescentes. Acredita-se comumente que a filosofia ajuda na emancipação do jovem estudante, construindo um sujeito com autonomia de pensamento - papel este que não é exclusivo da filosofia, mas que é esperado de sua presença na educação básica. Associada a isso, há a necessidade implícita, nessa etapa do ensino, de que ocorra uma conexão dos conteúdos específicos com a vida do estudante, de modo que os conceitos estudados façam sentido e ressignifiquem a experiência e a visão de mundo do jovem.

Dado o presente contexto, é importante refletir sobre o que se espera da filosofia: o ensino de filosofia na educação básica é capaz de promover a autonomia de pensamento e estabelecer conexões entre a vida e os conceitos filosóficos? O que se quer com este trabalho é esboçar algumas possibilidades de contribuição do ensino de filosofia para a formação na educação básica e, partindo disso, pensar estratégias e práticas que estejam alinhadas com essas possibilidades. 


\section{Educação como autonomia em Kant}

Para o presente trabalho, é válida uma reflexão de Kant sobre a educação, a partir de ideias que contribuíram para o estabelecimento da educação na sociedade moderna. Buscar-seá uma análise de sua obra Sobre a pedagogia, que possibilitou o entendimento da educação como uma prática da liberdade, objetivando a autonomia das crianças.

A obra foi organizada em três partes. Na introdução, é feita uma análise da disciplina desde a infância visando a um desenvolvimento para a maturidade, sendo necessária para a formação humana. A segunda parte trata "Sobre a educação física", que aborda os cuidados com o corpo e a saúde. Por fim, a terceira parte, "Sobre a educação prática", dá contribuições voltadas à moral e à formação cultural, essenciais para uma convivência harmoniosa em sociedade.

A questão da educação permeia o pensamento de Kant, que a entende como o "processo inicial do esclarecimento da razão, que culmina obrigando o homem a ver-se como humanidade" (PINHEIRO, 2007, p. 13). Para o filósofo, existem vários obstáculos ao desenvolvimento do homem e da humanidade, fazendo com que a educação seja necessária somente por ela o indivíduo torna-se plenamente responsável. "O homem não pode se tornar um verdadeiro homem senão pela educação. Ele é aquilo que a educação dele faz. Note-se que ele só pode receber a educação de outros homens, os quais a receberam igualmente de outros." (KANT, 1999, p. 15)

Mas o que é o homem? Há aqui um duplo aspecto, ser biológico e ser racional, natureza e humanidade, sendo o segundo aspecto sempre uma espécie de resultado produzido pela educação. Nesse sentido, a educação está relacionada com uma ideia de progresso, que carrega consigo um ideal de perfeição do homem em vista de seu ingresso na humanidade. "Não se devem educar as crianças segundo o presente estado da espécie humana, mas segundo um estado melhor, possível no futuro, isto é, segundo a ideia de humanidade e de sua inteira destinação.” (KANT, 1999, p. 22) Percebe-se que o autor busca uma teoria da educação em que a ideia de humanidade é a orientadora do progresso. Esse progresso seria como que impulsionado pelos obstáculos, dando início à reflexão; a partir disso, ocorreria a passagem do homem natural para a humanidade racional. A humanidade, para Kant, se encontraria no campo de uma natureza racional. É preciso deixar claro que tal conceito não está 
relacionado com uma natureza humana, mas sim com a racionalidade que faz com que o homem dê um princípio de ação e seja levado a agir a partir de tal princípio.

Esse duplo aspecto que constitui o ser humano é expresso em dois âmbitos: o fenomênico e o numênico. "O primeiro é representado pela condição de cidadania do indivíduo na sociedade, e o segundo pela liberdade desse indivíduo, agora sujeito moral." (PINHEIRO, 2007, p. 38) O papel da educação diante dessa perspectiva é estabelecer a ligação possível entre esses dois mundos, dando sua contribuição para o progresso citado anteriormente. Vale ressaltar que o homem é uma unidade, mas só podemos observar cada face separadamente.

Percebe-se que a educação é um problema para o homem. Analisando o célebre texto kantiano Resposta à pergunta: o que é Esclarecimento? (Beantwortung der Frage: Was ist Aufklärung?), conclui-se que a saída da menoridade, necessária ao esclarecimento, depende da educação. Assim, coloca-se a questão da possibilidade de passagem da sensibilidade ao entendimento, superando as adversidades impostas pela natureza e levando o homem a sua mais alta destinação. "Não cabe ao indivíduo a tarefa de conseguir atingir o fim supremo, mas à humanidade.” (PINHEIRO, 2007, p. 61)

Acima, foi dito que a educação em Kant se daria em uma prática da liberdade, mas de que forma? Como ensinar a liberdade? A liberdade deve ser pensada sempre visando a humanidade:

Kant nos ensina, na Crítica da razão pura, que o objeto desejado, quer seja todo o fenômeno, ou a prova da liberdade, é inacessível ao indivíduo, por ele não ser objeto do conhecimento, mas, quando muito, de fé. Ora, a dificuldade sobre a questão da possibilidade de ensinar liberdade vai além dos limites do individualismo. Apenas quando se leva em conta a humanidade é possível pensar nas condições de possibilidade de ensino da liberdade. (PINHEIRO, 2007, p. 72)

Pode-se perceber que a educação visa ao alcance da humanidade e ao estabelecimento de uma racionalidade que faça com que os seres humanos sejam levados a agir. Essa seria a meta final da espécie, que, para Kant, é a realização de uma constituição política perfeita. Nesse sentido, política e educação são indissociáveis.

Até agora, analisou-se um entendimento sobre o processo de educação em Kant. Mas o que seria, então, a pedagogia? Em que situação fica a filosofia perante essa problemática? O filósofo entende que a educação se constitui como um processo filosófico, e a pedagogia se caracteriza como uma ciência da educação. Então, a educação ocupa-se de fundamentar o que é o homem e qual é a sua tarefa no mundo, enquanto a pedagogia deve fazer com que essa destinação seja efetivada. 
No âmbito deste trabalho, devem-se pensar alternativas para que a filosofia no ensino básico cumpra essa destinação, que é a promoção da autonomia do pensamento. Um dos possíveis caminhos para a realização desse projeto é o entendimento do que Kant propõe:

No cultivo da razão é preciso praticar o método de Sócrates. [...] contudo, devemos proceder de tal modo que busquem por si proceder de forma a perseguir por si mesmas esses conhecimentos, ao invés de inculcar-lhes. O método socrático deveria constituir a regra do método catequético. (KANT, 1999, p. 70)

O método socrático se daria através da apresentação de uma série de problemas e, a partir destes, faria com que os estudantes efetuassem um julgamento. Esse procedimento, para Kant, se diferiria de um método mecânico de ensino. Através do método socrático, o ser humano pode atingir o uso pleno da razão em termos kantianos.

Dessa forma, a tarefa fundamental da educação é dar mecanismos para que o homem se torne moral. Mas isso só ocorrerá se ele puder pensar por si mesmo, sendo autônomo, capaz de dar a si mesmo leis que possam ser universais.

É, portanto, nesse ponto que a filosofia na educação básica se faz necessária e pode auxiliar o desenvolvimento de um pensamento autônomo. O que se quer é pensar possibilidades do ensino de filosofia na educação básica como desenvolvimento da autonomia do pensamento.

3. Uma proposta para o desenvolvimento da autonomia a partir do ensino de Filosofia Política

A fundamentação da intervenção em questões pedagógicas mais próximas do fazer se dará a partir de dois suportes: a gamificação e a aprendizagem baseada em projetos.

Gamificação é um conceito amplo e não necessariamente remete à construção de um jogo nos moldes habituais. No contexto desta intervenção, não se trata da criação de um jogo ou de uma atividade lúdica específica para tal proposta. A abordagem se aproxima mais da ideia de aplicar a gamificação em processos de aprendizagem, em que "estar baseado em games implica na construção de um sistema no qual aprendizes, jogadores [...] se engajarão em um desafio abstrato, definido por regras claras, interagindo e aceitando feedback com o alcance de

\footnotetext{
${ }^{2}$ Gamificação é uma apropriação para o português da palavra inglesa gamification. O termo remete ao uso de dinâmicas e mecânicas de jogos em processos de ensino e aprendizagem.
} 
resultados" (ALVES, 2014, p. 27). Basicamente, seria inserir a linguagem de jogos em uma situação de ensino e aprendizagem, com a definição de fases, a ideia de progressão, uma narrativa, desafios, recompensas e níveis.

Esses elementos da proposta de gamificação em um processo de ensino e aprendizagem estarão associados ao trabalho com projetos:

A aprendizagem baseada em projetos é um modelo de ensino que consiste em permitir que os alunos confrontem as questões e os problemas do mundo real que consideram significativos, determinando como abordá-los e, então, agindo cooperativamente em busca de soluções. (BENDER, 2014, p. 9)

Os projetos consistem na preparação, no planejamento e na execução de situações que favorecem o desenvolvimento da aprendizagem a partir da colaboração entre os pares, do incentivo à pesquisa e do feedback contínuo.

$\mathrm{O}$ que se quer é agregar elementos dessas duas propostas - a gamificação e a aprendizagem por projetos - com o objetivo de criar uma intervenção que esteja ligada à linguagem do jovem e que possa auxiliar o desenvolvimento da autonomia do pensamento, estando conectada com a vida.

Para essa intervenção, foi escolhido o eixo estruturante de filosofia política. Essa escolha se dá de forma estratégica, visto que a filosofia política é uma área de conhecimento diretamente ligada à vida e ao cotidiano do estudante e, no atual contexto, é de extrema importância a reflexão filosófica sobre política com os jovens. Ademais, esse eixo está diretamente ligado também ao aporte teórico da pesquisa: o entendimento de Kant de que educação e política são indissociáveis.

Para o início dos trabalhos, deve ser feita uma sensibilização, introduzindo o eixo política e fundamentando teoricamente as discussões. Uma alternativa seria discutir com os estudantes a necessidade da política e algumas de suas especificidades, o que pode ser realizado através de um estudo de texto. Podemos citar como exemplo o texto Por que a política?, de André Comte-Sponville. A escolha do que abordar nessa etapa de sensibilização será feita de acordo com a experiência e o contexto do professor.

Em seguida, a ideia geral é dividir a sala em equipes, que na proposta serão partidos políticos os quais terão de criar planos de governo (políticas públicas) e lançar uma candidatura. É importante salientar que deve-se tomar cuidado para caracterizar os fundamentos filosóficos de todo o processo, visto que a criação de partidos políticos em si não é da especificidade da filosofia. 
As etapas da proposta são:

- Partidos políticos;

- Plano de governo;

- Debate;

- Eleição.

A proposta de trabalho para as duas primeiras etapas é que os grupos criem um documento (trabalho escrito) e socializem os resultados em uma apresentação para a turma.

\subsection{Partidos políticos}

\begin{tabular}{|c|c|}
\hline O que fazer & Fundamentação filosófica \\
\hline $\begin{array}{l}\text { (1) Cada equipe receberá, por sorteio, uma } \\
\text { orientação do espectro político (extrema } \\
\text { esquerda, esquerda, centro-esquerda, centro, } \\
\text { direita, centro-direita, direita e extrema } \\
\text { direita); } \\
\text { (2) Criar um partido político fictício de } \\
\text { acordo com a orientação do espectro } \\
\text { recebida. } \\
\text { a) Sigla (A sigla diz respeito à ideologia } \\
\text { defendida pelo partido) } \\
\text { b) Ideologia do partido (ideais que o movem) } \\
\text { c) Organização (quem é quem no seu } \\
\text { partido?), cargos, funções. } \\
\text { d) Expressão dos interesses de classe (que } \\
\text { grupos pretendem representar?) } \\
\text { e) Qual o modelo de economia que } \\
\text { defendem? } \\
\text { f) Qual o modelo de estado que defendem? }\end{array}$ & $\begin{array}{l}\text { Sugestões de fragmentos a serem escolhidos: } \\
\checkmark \text { BOBBIO, Norberto. Direita e } \\
\text { esquerda: razões e significados de uma } \\
\text { distinção política. 3. ed. São Paulo: } \\
\text { Unesp, 2011. } \\
\checkmark \text { ROTHBARD, Murray. Esquerda e } \\
\text { direita: Perspectivas para a liberdade. } \\
\text { Campinas: Vide Editorial, 2016. }\end{array}$ \\
\hline
\end{tabular}

Entende-se que a elaboração de partidos políticos não é um trabalho próprio da filosofia, mas é imprescindível às etapas posteriores. Assim, deve haver um cuidado para fundamentar filosoficamente o espectro político e todo o trabalho de construção dos pressupostos ideológicos do partido.

\subsection{Plano de governo}




\begin{tabular}{|l|}
\hline O que fazer \\
\hline (1) Os partidos devem lançar candidatos para \\
presidente e vice-presidente. \\
(2) Criar um plano de governo é uma obrigação \\
para todos os candidatos. Desta forma, deve ser \\
criado um plano de governo que contenha \\
propostas para as áreas de educação, política \\
econômica, segurança e programas sociais \\
(sugestões). \\
(3) As propostas devem estar de acordo com a \\
ideologia do partido e fundamentadas \\
filosoficamente.
\end{tabular}

\section{Fundamentação filosófica}

Em fragmentos que podem ser escolhidos dos seguintes temas e autores:

\section{$\underline{\text { Público/privado }}$}

Habermas

$\checkmark$ HABERMAS, Jürgen. Mudança estrutural da esfera pública: investigações quanto a uma categoria da sociedade burguesa. Rio de Janeiro: Tempo Brasileiro, 1984.

Justiça

Platão

$\checkmark$ PLATÃO. A República. 7. ed. Trad. Maria Helena da Rocha Pereira. Lisboa: Fundação Calouste Gulbenkian, 1993.

Thomas More

$\checkmark$ MORE, Thomas. Utopia. São Paulo: Autêntica, 2017.

John Rawls

$\checkmark$ RAWLS, John. Uma teoria da justiça. São Paulo: Martins Fontes, 2000.

\section{Política e religião}

Robespierre

$\checkmark$ ROBESPIERRE, Maximilien. Discursos e relatórios na convenção. São Paulo: Contraponto, 1999.

John Locke

$\checkmark$ LOCKE, John. Carta acerca da tolerância. São Paulo: Abril Cultural,1973.

Separação dos poderes

Aristóteles

$\checkmark$ ARISTÓTELES. Política. Brasília, EdUnB, 1978.

Montesquieu

$\checkmark$ MONTESQUIEU, Charles. Do espírito das leis. São Paulo: Abril Cultural, 1979.

Liberdade

Michel Foucault 
$\checkmark$ FOUCAULT, Michel. Vigiar e punir. Petrópolis: Vozes, 2000.

Direito natural

Thomas Hobbes

$\checkmark$ HOBBES, Thomas. Leviatã. São Paulo: Abril, 1979.

John Locke

$\checkmark$ LOCKE, John. Dois tratados sobre o governo. São Paulo: Martins-Fontes, 1998.

Jean-Jacques Rousseau

$\checkmark$ ROUSSEAU, Jean-Jacques. $O$ Contrato Social. 19. ed. Rio de Janeiro: Ediouro, 1999.

Immanuel Kant

$\checkmark$ KANT, Immanuel. A metafísica dos costumes. Bauru: Edipro, 2003.

Direitos Humanos

Declaração dos Direitos do Homem e do Cidadão

$\checkmark$ Declaração dos Direitos do Homem e do Cidadão. In: HUNT, Lyn. A invenção dos direitos humanos: uma história. São Paulo: Companhia das Letras, 2009. p. 225-226.

Hannah Arendt

$\checkmark$ ARENDT, Hannah. As origens do totalitarismo. São Paulo: Companhia das Letras, 2013.

Ética e política

Aristóteles

$\checkmark$ ARISTÓTELES. Ética a Nicômaco. São Paulo: Nova Cultural. 1991.

Maquiavel

$\checkmark$ MAQUIAVEL, Nicolau. $O$ príncipe. São Paulo: L\&PM Editores: Porto Alegre, 2011.

$\underline{\text { Liberalismo social }}$

Keynes 


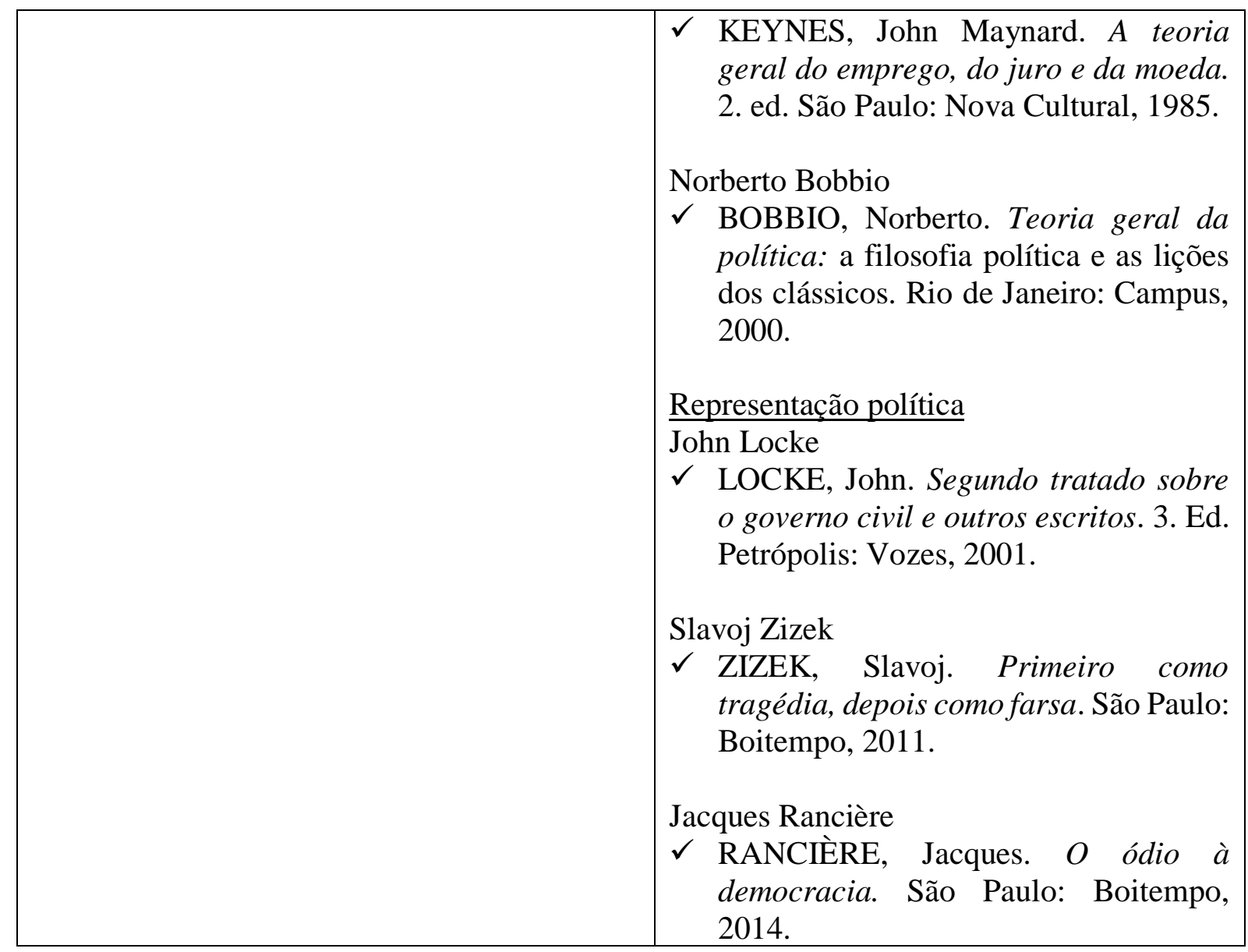

Nessa etapa, o trabalho pode se dar de diversas formas: (1) selecionar alguns textos e discuti-los em sala; a partir desses fragmentos, os estudantes desenvolverão políticas públicas. (2) selecionar textos e, como atividade de casa, os estudantes desenvolverão as políticas públicas, e o professor orientará os resultados do trabalho das equipes em sala. Há diversas formas de trabalhar esse tópico, o que vai depender da realidade de cada professor.

\subsection{Debate}

A sugestão é que o debate ocorra em três blocos. No primeiro bloco, cada partido terá um minuto para explicitar as propostas que achar mais interessantes para o contexto. No segundo bloco, cada candidato responderá a perguntas elaboradas anteriormente por eleitores indecisos, podendo dar respostas de até um minuto. No terceiro e último bloco, os candidatos perguntarão entre si. Cada candidato elaborará uma pergunta a seu oponente sorteado. As perguntas deverão ter no máximo 30 segundos. O candidato a quem se dirige a pergunta terá até um minuto para a resposta; em seguida, aquele que perguntou terá 
30 segundos para a réplica; por fim, o outro candidato terá 30 segundos para a tréplica.

\subsection{Eleição}

Como proposta de uma experiência democrática, sugere-se uma eleição. Contudo, como todos os estudantes da turma estarão envolvidos nos partidos políticos, talvez seja natural que eles queiram votar no partido que estavam representando. Cabe ao professor conscientizá-los de que, na etapa da eleição, todos os demais devem se considerar apenas eleitores e escolher as melhores propostas segundo as convicções políticas que construíram durante o projeto. Uma alternativa seria realizar o debate tendo outra turma como público, de modo que os votantes não estejam diretamente ligados às propostas apresentadas.

\section{Proposta de avaliação dos resultados esperados}

Tendo presentes as discussões teóricas sobre o processo avaliativo em filosofia, consonantes com as orientações institucionais do Ministério da Educação, os resultados esperados serão avaliados por etapas bem definidas e evidenciadas como produtos, a saber: (1) partidos políticos; (2) políticas públicas; (3) debate; e (4) eleições. Cada etapa pode ser avaliada com critérios definidos entregues anteriormente aos estudantes, para que os mesmos tenham um norte na etapa de produção.

A cada etapa, os estudantes receberão um retorno sobre o que desenvolveram e, a partir disso, projetarão a próxima. Evidencia-se assim uma avaliação formativa.

\section{Considerações Finais}

Pode-se dizer que há fortes evidências para fundamentar a contribuição da filosofia para a autonomia do pensamento. Verifica-se isso a partir da fundamentação, em Kant, de uma educação que contribua para o ideal de humanidade. Mas como a filosofia na educação básica auxilia nessa tarefa? Propôs-se aqui uma prática que tenta dialogar 
com o desenvolvimento da autonomia e fazer com que o estudante seja partícipe do processo de ensino e aprendizagem.

Dessa forma, a prática pedagógica proposta dialoga com o autor da fundamentação teórica no tocante à ideia de Kant de apresentar uma série de problemas para que o estudante faça um julgamento, com vistas ao desenvolvimento de sua autonomia. 
Referências

ALVES, Flora. Gamification: como criar experiências de aprendizagem engajadoras. Um guia completo: do conceito à prática. DVS Editora, 2014.

BENDER, William. Aprendizagem baseada em projetos: educação diferenciada para o século XXI. Porto Alegre: Editora Penso, 2014.

PINHEIRO, Celso de Moraes. Kant e a educação. Caxias do Sul: Educs, 2007.

KANT, Immanuel. Sobre a pedagogia. 2. ed. Piracicaba: Unimep, 1999.

NUSSBAUM, Martha. Sem fins lucrativos: por que a democracia precisa das humanidades. São Paulo: Martins Fontes, 2015. 